\title{
Clumped methane isotopes: New insights into origin and formation mechanisms of natural gases and a potential geothermometer
}

\author{
DR. NINA ALBRECHT ${ }^{1}$, NIVEDITA THIAGARAJAN ${ }^{2}$, \\ HAO XIE ${ }^{2}$, GUANNAN DONG ${ }^{2}$, ISSAKU E. KOHL ${ }^{1}$ AND \\ JOHN EILER ${ }^{3}$ \\ ${ }^{1}$ Thermo Fisher Scientific (Bremen) $\mathrm{GmbH}$ \\ ${ }^{2}$ California Institute of Technology \\ ${ }^{3}$ Caltech \\ Presenting Author: nina.albrecht@thermofisher.com
}

The isotopic characterization of geological gas deposits is crucial for the exploration of resources for global energy production. Methane $\left(\mathrm{CH}_{4}\right)$ is a primary constituent of natural gas reservoirs and in addition to its commercial importance it also plays a major role in the global carbon cycle. It is involved in various fluxes within atmospheric, microbial, hydrothermal and magmatic systems, and it is a potential factor in the anthropogenic acceleration of climate change.

The commonly measured molecule average ('bulk') isotope compositions of methane, $\delta^{13} \mathrm{C}$ and $\delta \mathrm{D}$, are determined by conventional IRMS. They are valuable tools to aid identification of methane's origins but are often ambiguous with respect to provenance and formation conditions. Also, they do not record gas formation temperatures.

The doubly-substituted ('clumped') isotope signatures of methane, $\Delta^{13} \mathrm{CH}_{3} \mathrm{D}$ and $\Delta^{12} \mathrm{CH}_{2} \mathrm{D}_{2}$, can be analyzed by HighResolution IRMS (HR-IRMS) [1]. They provide two new independent constraints that can resolve ambiguities in methane provenance and add fresh tools for understanding the environments and chemical mechanisms of natural methane formation [2-6].

We highlight the scientific added value of combined bulk isotope and clumped isotope compositions of methane and show how they (i) refine the forensic identification of methane sources, (ii) aid in recognition of methane's formation mechanisms, and (iii) can be utilized as a natural geothermometer in cases where the gas formed in internal thermodynamic equilibrium [7].

[1] Eldrigde et al. (2019) ACS Earth Space Chem 3, 27472764; [2] Dong et al. (2020) GCA (submitted); [3] Thiagarajan et al. (2020) PNAS 117(8), 3989-3995; [4] Thiagarajan et al. (2020) GCA 275, 188-208; [5] Thiagarajan et al. (2021) $A A P G$ (under review); [6] Xie et al. (2021) GCA (submitted); [7] Dong et al. (2021) Thermo Scientific Whitepaper WP30767, 1-13. 